\title{
The Measures of the Persian Medicine Vis- à -vis the Treatment of Premature Ejaculation
}

\section{Somaye Mahroozade*and Azam Abdolahadi}

Department of Complementary Medicine, Research Institute for Islamic and Complementary Medicine, Iran University of Medical Sciences and Health Services, Tehran, Iran

*Corresponding author: Mahroozade S, Department of Complementary medicine, Research Institute for Islamic and Complementary Medicine, Iran University of Medical Sciences \& Health Services, Tehran, Iran, Tel: 989122135426; Fax: 00982155613191, E-mail: dr.mahroozade@gmail.com

Received date: January 02, 2018; Accepted date: January 14, 2018; Published date: January 19, 2018

Copyright: (c) 2018 Mahroozade S, et al. This is an open-access article distributed under the terms of the Creative Commons Attribution License, which permits unrestricted use, distribution, and reproduction in any medium, provided the original author and source are credited.

\section{Abstract}

Premature ejaculation is a male sexual dysfunction characterized by ejaculation which occurs within about one minute of vaginal penetration and inability to delay ejaculation on the vaginal penetrations. The individuals suffering from the premature ejaculation will reach orgasm before even the minimal penile or sexual stimulation, prior to or immediately after penetration. Premature ejaculation is the most prevalent male sexual dysfunction. It has detrimental effects on the relationship of the partners; it may cause mental distress, anxiety, and depression. Its prevalence rates run the gamut from $20 \%$ to $30 \%$.

The etiology of this problem is unknown, yet again there are some hypotheses in this regard including anxiety, penile hypersensitivity, and serotonin receptor dysfunction.

The use of the Persian Medicine and herbal remedies for the treatment of diseases has a long historical background. Nutrition is the principal stepping stone of the treatment in the Persian Medicine; it proffers various food and remedy options for treating premature ejaculation. Therefore, the authors of the present paper aimed at taking into account the nutritional advice and suggestions of the Persian Medicine to ameliorate the aforementioned issue.

In this review article, the seminal and original books of the Persian Medicine on the male sexual dysfunction have been thoroughly reviewed.

A list of available, inexpensive and effective foods and medications which has been experienced for centuries was elicited. Due to the prevalence and the effects of the premature ejaculation on both marital relationships and subsequently fertility, constructing treatments like this list can be efficacious for to solving this problem.

Keywords: Premature ejaculation; Persian medicine; Sexual dysfunction; Ejaculation

\section{Introduction}

Also called early ejaculation, rapid ejaculation, premature ejaculation is one of the most common sexual disorders in men-with an estimated prevalence of $30 \%$ in the world. The individuals suffering from the premature ejaculation will reach orgasm before even the minimal penile or sexual stimulation, prior to or immediately after penetration. In fact, this disorder is referred to the situation in which first the interval between the moments of penetration to the ejaculation is unusually short and the ejaculation occurs before or shortly after the penetration. Second, the person has no control over his ejaculation.

Third, this condition causes mental and psychological pressure or dissatisfaction for the affected person, his partner or both. Men with premature ejaculation tend to report less sexual satisfaction than men who have a normal ejaculation delay. The etiology of this problem is unknown, and there are some hypothesis, including anxiety, penile hypersensitivity, and serotonin receptor dysfunction [1].
Due to its prevalence and its effects on both marital relationships and subsequently fertility, understanding the causes and treatment of premature ejaculation is of paramount importance. The Persian medical scholars deem nutrition and the rectification of the lifestyle to be quintessential for the bodily health and the reproductive system accordingly [2]. In this regard, the authors of the present study aimed at garnering a sundry of nutrition strategies or measures zoomed particularly on treating premature ejaculation through an extensive scrutiny of the literature available on the traditional medicine. The purpose of this study is proffering explanations for the causes of this problem and providing a typology of food items recommended for the improvement or treatment of this irksome disorder.

\section{Methodology}

In this mini review article, the seminal and original books of the Iranian traditional medicine on the male sexual dysfunction have been reviewed. The criteria for selecting the sources are as follows:

The authors who penned these works happen to be amongst the most renowned scholars in the traditional medical history.

Their authors have been both well-versed in theory and extremely experienced in praxis. 
Their writers, in addition to practicing medicine, were remarkably successful in writing and therefore could pencil their thoughts on the topic vividly.

The authors have been elicited from various centuries of medical history. These sources include the Canon of Medicine by Avicenna (Ibn Sina, $11^{\text {th }}$ century AD), Al-Hawi by Razi ( $9^{\text {th }}$ century AD), Zakhireye Khwarazmshahi by Ismail Gorgani ( $11^{\text {th }}$ century AD), Ekseer e Azam by Hakeem Muhammad Azam Khan (19 ${ }^{\text {th }}$ century AD) and Tibb-i Akbari (an expanded version of the Arabic treatise Sharh al-asbab waal-'alamat ) by Muhammad Muqim Arzani ( $18^{\text {th }}$ century AD) and the Summary of Wisdom (Kholāsa Al-Hekma) by Mohammad Hossein Aghili Khorasani( $13^{\text {th }}$ century AD), amongst others.

The aforementioned works were browsed thoroughly with germane keywords like premature ejaculation and food and nutrition recommendations and measures for premature ejaculation treatment.

Razi and Jorjani and Avicenna believed that patients must be treated with food as far as possible. Abu Zeid Balkhi, who was Razi's master, professed that food is the first thing to be noted and carefully considered in maintaining health. Under the section on Treatment he mentioned that drugs should be avoided unless it is absolutely needed, because unlike food, drugs are in contrast with human nature. Nazem Jahan wrote, "For increasing sexual power, food has more advantages than drugs" $[2,3]$.

In the present research, a list of useful foods and nutrition in the Persian Medicine was gathered which is available to the general public; therefore, their inclusion in the diet of the individuals can be efficacious for the treatment merged with other conventional methods. In various recent studies, the role of many of these substances has been confirmed in ameliorating the premature ejaculation.

\section{Findings}

Perusing the pertinent literature, one cannot help but notice that premature ejaculation has been always the cynosure of attention for the Persian scholars; in many available sources, miscellaneous food items and nutrients have been recommended for its treatment [4].

The pioneers of the Persian medicine, like Avicenna (Ibn Sina), held that simultaneous orgasms of both males and females during copulation would be ideal for a consummate gestation to occur. In this regard, apart from providing some measures and suggestions during coitus, they zoomed on the Couples' orgasm synchronization [5].

Jorjani has written: Rapid ejaculation has four causes: excessive semen volume, thin watery semen, hot temperament of semen, and weakness of retentive power of seminal tracts. He has mentioned lowfrequency intercourse, thin semen, burning sensation on ejaculation, and ejaculation without enough erection as signs of these causes, respectively. He suggested different treatment modalities according to the causes of the disease and temperaments $[6,7]$.

From the perspective of the Persian Medicine, the treatment for all disease or maladies in general and male sexual dysfunction in particular boils down to proper nutrition.

In this view, the cause of ejaculation speed is categorized into four main groups and based on the cause, appropriate treatment is provided.
The increase of coldness and wetness in the genitals: as an explanation of these patients it can be posited that their semen is too much diluted and the color approaches whiteness. These people usually do not have high libido or sex drive. On the other hand, the color of their urine is yellowish-white. The roster of foods that can help these patients include pistachios, almonds, cinnamon, saffron, hazelnuts, carrot seeds, alfalfa, stinging nettle (Urtica dioica), ginger jam, Abgoosht (or Dizi: an Iranian stew) with warm spices, cooked peas, turnips, coconut, flaxseed, sesame, carrot jam and milk and honey. Furthermore, these people should avoid taking dough (a savory yogurt-based beverage (and yogurt. Oiling the testicles with chamomile oil and exercise are very much recommended for these patients. Moreover, the frequency of intercourse should not exceed once or twice per week.

The increase in warmness and wetness: semen has a moderate texture and massive volume; these individuals have high physical strength and have a lot of libido; the color of their urine is strong yellow and the color of the semen tends to be yellowish. Swollen veins/ arteries of testicles are evident in these individuals. These people have the proclivity to quaff cool water.

Recommended measures for these people: having cranberry, lemon sharbat [1], orange sharbat, sweet dough, pomegranate juice, pomegranate, milk, cucumber, common purslane plant, barberry, plum, orange juice, raspberries, rice, vegetables, verjuice ash (a thick soup/stew, which is usually served hot), spinach, oiling by violet unction and consuming foods which happen to be replete with vegetables.

The pungency of semen: the patient feels warm when the semen exits; the color of the fluid in these people is yellow. If the temperature of the semen is high, the semen is concentrated. However, if the temperature of the semen is not reached to the extreme, the liquid is diluted. These people tend to partake of cold foods and drinks. The consumption of lettuce seeds, tiger lotus flower sharbat or syrup, violet sharbat, rosé flower sharbat, chicory, dough and yogurt, tamarind (Tamarindus indica), Barberry juice, barley and jujube can be a great boon to these people.

Weakness of the main organs of the body: the main organs of the body are those which are vital to the survival of the person and his offspring. These organs include the brain, the heart, the liver and the testicles (and in women, the ovaries). The strength of these members is absolutely essential for the proper sexual performance.

People who have weakness in core organs of the body tend to have low sexual desire; they suffer from erectile dysfunction, ejaculation without proper erection and weakness in pulse.

They also experience loss of body heat, lethargy, severe general weakness, shortness of breath and sweating. Use of rich foods such as pealed peanut with sugar, cooked bird meats with peas, saffron, cinnamon and clove, kebab, meat extracts, figs, apple, quince, rose water, grapes, black corinth, hazelnuts, mung beans, eggs, honey and shrimp can be beneficial for these individuals [7-13].

Psychological causes: Other causes of premature ejaculation include depression, anxiety, and severe phobia. The use of brewed lemon balm, chamomile, basil, lavender, orange blossom, apple juice and rose water are useful for these people (Table 1). 
Citation: Mahroozade S, Abdolahadi A (2018) The Measures of the Persian Medicine Vis-à-vis the Treatment of Premature Ejaculation. Altern Integr Med 7: 258. doi:10.4172/2327-5162.1000258

Page 3 of 4

\begin{tabular}{|c|c|c|c|}
\hline Common Name & Scientific name & Iranian Traditional name & Indication in Premature Ejaculation Types \\
\hline Cinnamon & Verum cinnamon & Darcin & $\begin{array}{l}\text { The increase of coldness and wetness in the genitals/ Weakness of the main } \\
\text { organs }\end{array}$ \\
\hline Saffron & Crocus sativus & Zaferan & $\begin{array}{l}\text { The increase of coldness and wetness in the genitals/ Weakness of the main } \\
\text { organs }\end{array}$ \\
\hline Hazelnuts & Corylus avellana & Fandogh & $\begin{array}{l}\text { The increase of coldness and wetness in the genitals/ Weakness of the main } \\
\text { organs }\end{array}$ \\
\hline Carrot seeds & Subsp sativus & Bazre jazar & The increase of coldness and wetness in the genitals \\
\hline Alfalfa & Medicago sativa & Yonje & The increase of coldness and wetness in the genitals \\
\hline Ginger & Zingiber officinale & Zanjebil & The increase of coldness and wetness in the genitals \\
\hline Sesame & Sesamum indicum & Konjed & The increase of coldness and wetness in the genitals \\
\hline Coconut & Cocos nucifera & Nargil & The increase of coldness and wetness in the genitals \\
\hline Carrot & Subsp sativus & Jazar & The increase of coldness and wetness \\
\hline Pea & Cicer arietinum & Nokhod & $\begin{array}{l}\text { The increase of coldness and wetness in the genitals/ Weakness of the main } \\
\text { organs }\end{array}$ \\
\hline Turnip & Brassica rapa & Shalqam & The increase of coldness and wetness in the genitals \\
\hline flaxseed & Linum usitatissimum & Bazre Katan & The increase of coldness and wetness in the genitals \\
\hline $\begin{array}{l}\text { Stinging nettle } \\
\text { seeds }\end{array}$ & Urtica dioica & Anjore & The increase of coldness and wetness in the genitals \\
\hline Almond & Prunus dulcis & Badam & $\begin{array}{l}\text { The increase of coldness and wetness in the genitals/ Weakness of the main } \\
\text { organs }\end{array}$ \\
\hline Coriander & Coriandrum sativum & Geshniz & The increase in warmness in the genitals \\
\hline Pomegranate juice & Punica granatum extract & Ab Anar & The increase in warmness in the genitals/ pungency of semen \\
\hline Sweet dough & sweet dough & Dough & The increase in warmness in the genitals/ pungency of semen \\
\hline Barberry & Berberis vulgaris & Zereshk & The increase in warmness in the genitals/ pungency of semen \\
\hline Raspberry & Rubus strigosus & Tameshk & The increase in warmness in the genitals \\
\hline Rice & Oryza sativa & Oroz & The increase in warmness in the genitals \\
\hline Pomegranate flower & Punica granatum & Golnar & The increase in warmness in the genitals \\
\hline Santalum & Santalum album & Sandal & The increase in warmness in the genitals \\
\hline Sumach & Rhus coriaria & Somagh & The increase in warmness in the genitals \\
\hline Portulaca & Portulaca oleracea & Khorfeh & The increase in warmness in the genitals \\
\hline Myrtus & Myrtus communis & Murd & The increase in warmness in the genitals \\
\hline Oxymel & Oxymel & Sekanjabin & The increase in warmness in the genitals \\
\hline Verjuice & Verjuice & Ab Ghureh & The increase in warmness in the genitals \\
\hline Lettuce seeds & Lactuca sativa & Bazre kahu & pungency of semen \\
\hline Tiger lotus & Nymphaea lotus & Niloofar & pungency of semen \\
\hline Violet & Viola odoratta & Banafshe & pungency of semen \\
\hline Rosé flower & Rosa damascena & vard & pungency of semen \\
\hline Chicory & Cichorium intibus & Casni & pungency of semen \\
\hline
\end{tabular}


Citation: Mahroozade S, Abdolahadi A (2018) The Measures of the Persian Medicine Vis-à-vis the Treatment of Premature Ejaculation. Altern Integr Med 7: 258. doi:10.4172/2327-5162.1000258

Page 4 of 4

\begin{tabular}{|c|c|c|c|}
\hline Yogurt & Yogurt & Mast & pungency of semen \\
\hline Tamarind & Tamarindus indica & Tamr & pungency of semen \\
\hline Jujube & Ziziphus jujuba & Anab & pungency of semen \\
\hline Figs & Ficus carica & Tin & Weakness of the main organs \\
\hline Apple & Malus pumila & Sib & Weakness of the main organs/ Psychological cause \\
\hline Quince & Cydonia oblonga & Safarjal & Weakness of the main organs/ Psychological cause \\
\hline Rose water & Aqua rosacea & Golab & Weakness of the main organs/ Psychological cause \\
\hline Grapes & Vitis vinifera & Angur & Weakness of the main organs \\
\hline Black Corinth & Zante currants & Maviz & Weakness of the main organs \\
\hline Hhazelnuts & Corylus colurna & Fandogh & Weakness of the main organs \\
\hline Pistachios & Pistacia vera & Fostogh & Weakness of the main organs \\
\hline Mung beans & Vigna radiata & Mash & Weakness of the main organs \\
\hline Honey & $\mathrm{Mel}$ & Asal & Weakness of the main organs \\
\hline Shrimp & Crangon crangon & Robian & Weakness of the main organs \\
\hline Clove & Syzygium aromaticum & Gharanfol & Weakness of the main organs \\
\hline Chamomile & Matrcaria chamomilla & Babune & Psychological cause \\
\hline Basil & Ocimum basilicum & Reyhan & Psychological cause \\
\hline Lavender & Nepeta menthoides & Ostokhodus & Psychological cause \\
\hline Lemon balm & Melissa officinalis & Bad-eranjbooye & Psychological cause \\
\hline orange blossom & Citrus sinensis & Bahar narenj & Psychological cause \\
\hline
\end{tabular}

Table 1: Natural remedies suggested for premature ejaculation by Persian medicine.

\section{Conclusion}

To wrap up, it can be safely construed that the use of nutritional supplements in traditional medicine, along with other modern treatments, can help patients ameliorate premature ejaculation to a considerable extent. It seems that combination of medical and herbal therapy can be beneficial in obtaining better result in treatment. More clinical trials are mandatory.

\section{References}

1. Hatzimouratidis K, Amar E, Eardley I, Giuliano F, Dimitrios H, et al. (2010) Guidelines on male sexual dysfunction: Erectile dysfunction and premature ejaculation. Eur Urol 57: 804-814.

2. Mahroozade S, Sohrabvand F, Sohrabvand F, Byvs S, Moderator I, Nazari SM, et al. (2012) Male infertility in Iranian traditional medicine, causes, treatment and compares it with modern medicine. Iran J Obstet Gynecol Infertil 18:1-11.

3. Nejatbakhsh F, Nazem E, Goushegir A, Nasrabadi AN, Isfahani MM, et al. (2012) Recommended foods for male infertility in Iranian traditional medicine. Iran J Reprod Med 10: 511-516

4. Sohrabvand F, Mahroozade S, Bioos S, Nazari SM, Dabaghian FH (2016) Improvement in sperm parameters with traditional iranian remedy: A case report. J Evid Based Complementary Altern Med.
5. Ibn Sina H (1991) Al-Qanun fi al-Tibb. Beirut, Lebanon: Dar alkotobalelmiyah.

6. Sharifi AR, Homayounfar A, Mosavat SH, Heydari M, Naseri M (2016) Premature ejaculation and its remedies in medieval Persia, Urol 90: 225-228.

7. Jorjani SI, Zakhire K (2013) Qom: Rehabilitation institute of natural medicine.

8. Kirmani N (2009) Sharh al asbab al alamat. Describing the reasons and symptoms. Correction and research by the Institute of natural medicine. Qom: Jalal al-Din.

9. Razi Z. Alhavy Altb (2000) Correction by Heisam taeemi, Dar Al Ehya, Al Arabi.

10. Aghili Khorasani MH (2012) Makhzan-Al Advieh. Tehran, Iran: Sabzarang.

11. Arzani MA. Tibb Akbari (2009) Qom: Rehabilitation institute of natural medicine.

12. Shirazi AK. Tehran: Institute of Islamic studies medical history; 2009.

13. Khan AM, Azam E. Tehran, Iran: The institute for medical historyIslamic and complementary Medicine, Tehran University of Medical Sciences; 2004. 